\title{
Development of an Empirical Model for the Health Improvement of Patients with Thyroidectomy
}

\author{
Seong-Ran Lee \\ Department of Medical Information, Kongju National University \\ lsr2626@naver.com
}

\begin{abstract}
The purpose of this study is to develop an empirical model for the health improvement of patients with thyroidectomy. Subjects of this study were patients who visited general surgery in K general hospital from January 7 to July 8, 2013. As a results, the present research showed that the mean score of stress control after intervention decreased significantly than subjects( $t=2.91, p=.038)$ before the intervention. Secondly, the present research showed that the performance ability rate of thyroidectomy can be increased to $52.7-68.4 \%$ by the intervention. The paper will contribute to the model of therapeutic lifestyle change program by the health promotion program's thyroidectomy patients and indicate the direction of their health promotion program adoption in the future.
\end{abstract}

Keywords: Development, Empirical Model, Health Improvement, Patients, Thyroidectomy

\section{Introduction}

Thyroid cancer is the most frequent endocrine tumor. It increased across the world, especially in micropapillary thyroid cancer under 1 centimeter. The Annual Report of the Korea Central Cancer Registry reported that the incidence of thyroid cancer was increased rapidly with higher rate than other countries in Korea and similar rate as incidence in the area exposed to radiation, although studies about high incidence rate and clinipathological characteristics of Korea were not yet performed [1-3].

The number of patients in Korea increased rapidly before 1990 to 2012 after 2000, with rates of papillary thyroid cancer from $88 \%$ before 1990 after 2000. The increment of proportions of micropapillary thyroid cancer was prominent from $11.3 \%$ before 1990 to $18.0 \%$ during 90-99 to $49.6 \%$ after 2000, suggesting that the increment of thyroid cancer was attributed to early diagnosis by health screening with neck ultrasonography and fine needle aspiration cytology [4-6].

The incidence of thyroidectomy cancer is steadily increasing in many countries including Korea. Especially in Korea, the incidence of thyroid cancer is very rapidly increasing during several decades: from 2012 Annual Report of the Korea Center Cancer Registry, thyroid cancer ranked the fourth among all cancers(incidence rate was 10.9\%). Moreover the incidence of thyroid cancer was $18.7 \%$ in female and now thyroid cancer was reported the most common cancer in Korean female. Among several thyroid cancers, papillary thyroid cancer is rapidly increasing due to the increased detection of papillary thyroid microcarcinoma [1,7].

The patients who had total thyroidectomy were undergoing radioactive iodine therapy. Postoperative nausea and vomiting is a common problem in patients recovering from anesthesia and surgery [8]. There were the health problems related to physical, emotional and psychological issues after thyroidectomy [9, 10]. Thus, we need to develop a health 
management program for thyroid surgery patients. In terms of method to establish the optimal management program about thyroidectomy patients, we should investigate clinical characteristics, prognosis and predictive factors of thyroidectomy patients.

In changes of pathological characteristics, rates of patients with lymph node involvement was reduced from $78.7 \%$ before 1990 to $59.3 \%$ during $90-99$ to $46.1 \%$ after 2000 , and those with extrathyroidal extension was also reduced from $65.7 \%$ before 1990 to $68.5 \%$ during 90 99 to $57.4 \%$ after 2000. Although these reductions resulted from increasing diagnosis by health screening, the degrees of reduction were less than the degree of increment of small size tumor $[1,11]$.

In order to solve the problem, we should look for the practical plans. There were few studies to deal with clinical application of predictive model for health promotion in patients undergoing thyroidectomy until present. The study designed to develop the long-term health intervention program and ultimately to analyze the intervention effect through its application. Therefore, the purpose of this paper is to develop an empirical model for the health promotion of patients with thyroidectomy. In addition, the program is to improve their quality of life and its effectiveness in health promotion, and to examine their satisfaction for the patients. This study may contribute to the development of care knowledge as basic materials of theoretic development that affects patients with thyroidectomy.

\section{Materials and Methods}

\subsection{Clinical Study Design}

This study is to construct effectively database system by making use of intervention effect method [Fig. 1]. The first step of the program development is to determine the necessity of the participants. The second step is to identify the functional elements of successful models and gather the information about this. In the third step, program formation which will be reflected in effectively database system is designed as part of information gathering and synthesis. The fourth step is the stage of information system analysis and design. In the fifth step, the stage of operation, where preliminary program is to be applied in the field has been implemented. The final step is to assess the effect of personal information and build up the procedure [Fig. 2].

\subsection{Study materials}

Subjects of this study were patients who visited general surgery in K general hospital from January 7 to July 8, 2013. 142 patients (experimental group 71, control group 71) were assigned to an experimental group and a control group among women who agreed to participate in intervention program.

\subsection{Study Methods}

General characteristics of study subjects were measured by percentage and number. The pairwise t-test was done to compare the before and after intervention effect for performance ability rate of clinical information. This was conducted to observe some significant differences between the two groups before and after the intervention effect program. 


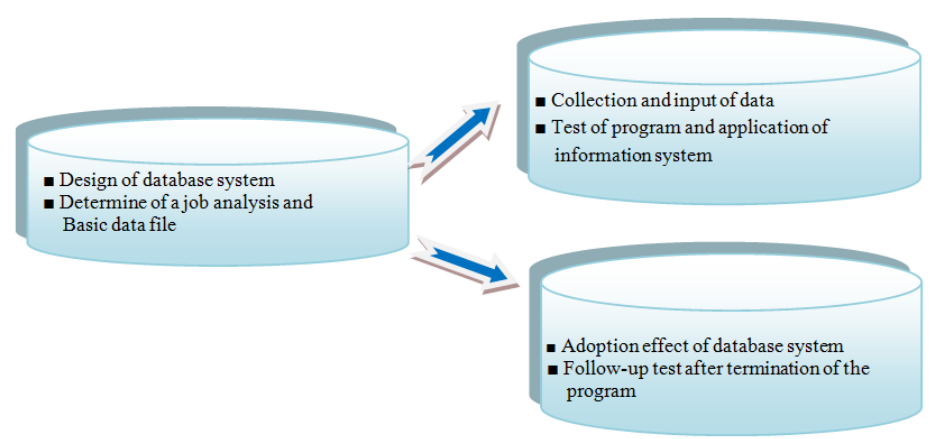

Figure 1. Predictive Model for Health Promotion of Thyroidectomy Patients

\section{Result}

\subsection{General Characteristics of Study Subjects}

Table 1 presents general characteristics of study subjects. Below table notes, the response rate $(59.2 \%)$ of experimental groups was statistically significantly higher than the response rate $(53.5 \%)$ of control group at female $\left(X^{2}=6.59, \mathrm{p}=.042\right)$ according to gender of subjects. The response rate $(40.8 \%)$ of experimental groups with another disease was significantly higher than the response rate $(22.5 \%)$ of control group with it in terms of another disease $\left(X^{2}=7.41\right.$, $\mathrm{p}=.015)$. On the other hand, for subjects with a family history, the response rate( $26.8 \%)$ of experimental group was significantly higher than the response rate(11.3\%) of control $\operatorname{group}\left(\mathrm{X}^{2}=5.78, \mathrm{p}=.039\right)$.

Table 1. General Characteristics of Study Subjects

\begin{tabular}{|c|c|c|c|c|}
\hline Variables & $\begin{array}{l}\begin{array}{c}\text { Experimental } \\
\text { group }\end{array} \\
\mathrm{N}(\%)\end{array}$ & $\begin{array}{c}\begin{array}{c}\text { Control } \\
\text { group }\end{array} \\
\mathrm{N}(\%)\end{array}$ & $\mathrm{x}^{2}$ & P \\
\hline \multicolumn{5}{|l|}{ Gender } \\
\hline Male & $29(40.8)$ & $33(46.5)$ & 6.59 & .042 \\
\hline Female & $42(59.2)$ & $38(53.5)$ & & \\
\hline \multicolumn{5}{|l|}{ Age } \\
\hline$\leq 29$ & $7(9.9)$ & $11(15.5)$ & 8.37 & .087 \\
\hline $30-39$ & $25(35.2)$ & $19(26.8)$ & & \\
\hline $40-49$ & $21(29.6)$ & $7(23.9)$ & & \\
\hline$\geq 50$ & $18(25.4)$ & $24(33.8)$ & & \\
\hline \multicolumn{5}{|l|}{ Marital status } \\
\hline Single & $21(29.6)$ & $8(25.4)$ & 5.49 & .281 \\
\hline Married & $50(70.4)$ & $53(74.6)$ & & \\
\hline \multicolumn{5}{|l|}{ Economic status } \\
\hline Less than 2 millions & $19(26.8)$ & $17(23.9)$ & 10.86 & .574 \\
\hline 2-2.99 millions & $21(29.6)$ & $14(19.7)$ & & \\
\hline $3-4.99$ millions & $11(15.5)$ & $19(26.8)$ & & \\
\hline Above 5 million & $20(28.2)$ & $21(29.6)$ & & \\
\hline \multicolumn{5}{|l|}{ Educational level } \\
\hline Less than & & & & - \\
\hline middle achool & $\begin{array}{r}9(12.7) \\
28(39.4)\end{array}$ & $13(18.3)$ & 13.52 & .069 \\
\hline High school & $\begin{array}{l}28(39.4) \\
34(47.9)\end{array}$ & $\begin{array}{l}30(42.3) \\
28(39.4)\end{array}$ & & \\
\hline \multirow{2}{*}{\multicolumn{5}{|c|}{ Other disease }} \\
\hline & & & 7.41 & .015 \\
\hline $\begin{array}{l}\text { Yes } \\
\text { No }\end{array}$ & $\begin{array}{l}29(40.8) \\
42(59.2)\end{array}$ & $\begin{array}{l}10(22.5) \\
55(77.5)\end{array}$ & & \\
\hline \multicolumn{5}{|l|}{ Occupation } \\
\hline Yes & $43(60.6)$ & $48(67.6)$ & 4.69 & .786 \\
\hline No & $28(39.4)$ & $23(32.4)$ & & \\
\hline \multirow{2}{*}{\multicolumn{5}{|c|}{$\begin{array}{l}\text { Family cancer } \\
\text { history }\end{array}$}} \\
\hline & & & & \\
\hline Yes & $19(26.8)$ & $8(11.3)$ & 5.78 & .039 \\
\hline No & $52(73.2)$ & $63(88.7)$ & & \\
\hline Total & $71(100.0)$ & $71(100.0)$ & & \\
\hline
\end{tabular}

\subsection{Comparison of Performance Ability Rate of Clinical Information}


Table 2 presents the comparison of performance ability rate of clinical information before and after intervention. Below table notes, according to the health practice scores after intervention, the mean score of stress control after intervention decreased significantly than subjects $(\mathrm{t}=2.91, \mathrm{p}=.008)$ before the intervention. And then behavioral change of vegetable intake after intervention was significantly higher compared to before the intervention $(\mathrm{t}=-5.82$, $\mathrm{p}=.042$ ).

Table 2. Comparison of Performance Ability Rate of Clinical Information

\begin{tabular}{|c|c|c|c|c|}
\hline Variables & $\begin{array}{c}\text { Before } \\
\text { Mean } \pm \text { S.D. }\end{array}$ & $\begin{array}{c}\text { After } \\
\text { Mean } \pm \text { S.D. }\end{array}$ & $\mathrm{t}$ & $P$ \\
\hline Stress control & $53.07 \pm 1.64$ & $36.27 \pm 1.92$ & 2.91 & .008 \\
\hline Exercise & $39.46 \pm 0.81$ & $59.63 \pm 0.48$ & -4.36 & .015 \\
\hline $\begin{array}{l}\text { Body weight } \\
\text { control }\end{array}$ & $71.53 \pm 1.64$ & $50.81 \pm 1.53$ & 8.14 & .037 \\
\hline Meat intake & $48.79 \pm 0.35$ & $37.45 \pm 0.27$ & 4.69 & .046 \\
\hline $\begin{array}{l}\text { Cholesterol } \\
\text { control }\end{array}$ & $57.16 \pm 1.56$ & $42.13 \pm 2.61$ & 1.35 & .051 \\
\hline Depression & $48.29 \pm 0.75$ & $45.72 \pm 0.288$ & 1.62 & .703 \\
\hline Hypertension & $51.42 \pm 0.48$ & $35.54 \pm 0.75$ & 7.95 & .025 \\
\hline $\begin{array}{l}\text { Blood sugar } \\
\text { control }\end{array}$ & $72.05 \pm 1.73$ & $52.96 \pm 0.23$ & 3.48 & .048 \\
\hline Overworking & $66.21 \pm 0.58$ & $49.28 \pm 0.51$ & 1.40 & .036 \\
\hline $\begin{array}{l}\text { Vegetable } \\
\text { intake }\end{array}$ & $41.57 \pm 0.9$ & $53.62 \pm 0.35$ & -5.82 & .042 \\
\hline Smoking & $52.84 \pm 0.57$ & $41.39 \pm 0.57$ & 0.29 & .027 \\
\hline Alcohol drinking & $52.36 \pm 0.39$ & $35.72 \pm 0.52$ & 4.63 & .015 \\
\hline $\begin{array}{l}\text { Life living } \\
\text { activity }\end{array}$ & $46.92 \pm 0.73$ & $37.58 \pm 0.64$ & 1.58 & .039 \\
\hline
\end{tabular}

\subsection{Durability of the Clinical Effect of Information Application}

Figure 2 presents the durability of the clinical effect of information application. The hypertensive change after two months by intervention was significantly different with experimental group compared to control group $(\mathrm{p}<.05)$. The diabetes mellitus decreased significantly compared with the control group $(\mathrm{p}<.05)$. Vegetable intake increased in both the experimental and control group. However, after six months it increased steadily in the experimental group but rather decreased in the control group. 


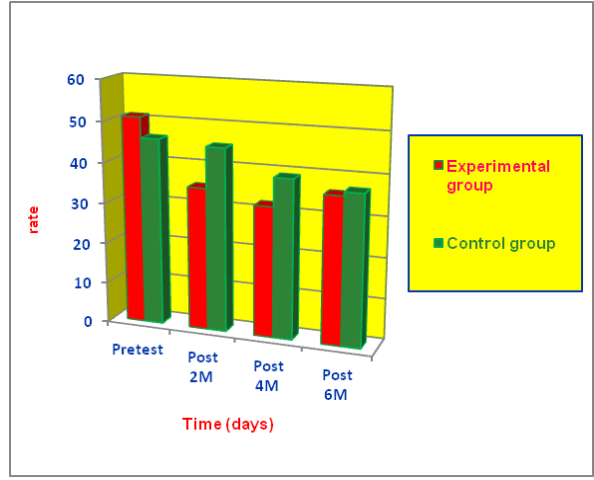

A. The Change of Hypertension

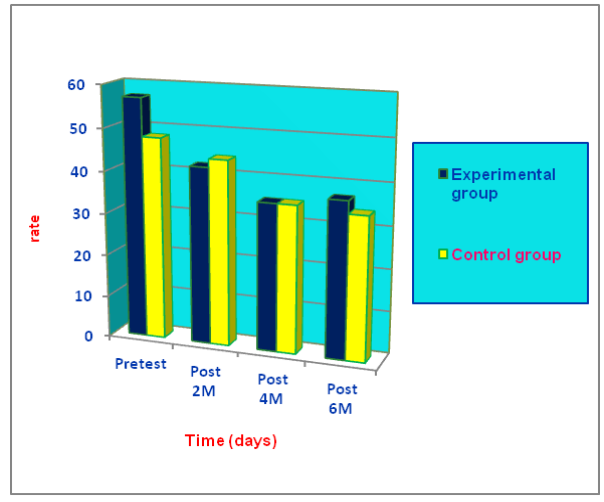

C. The Change of Cholesterol

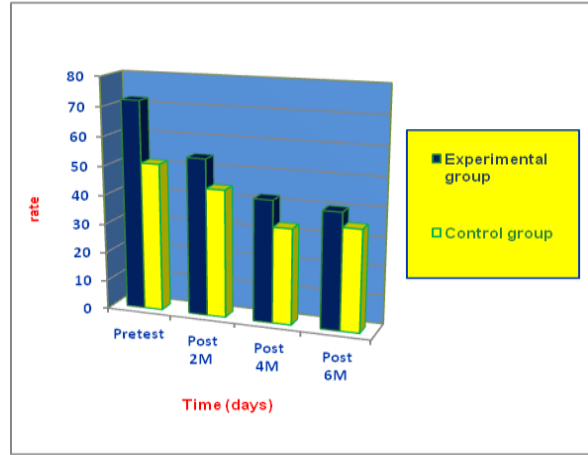

B. The Change of Diabetes Mellitus

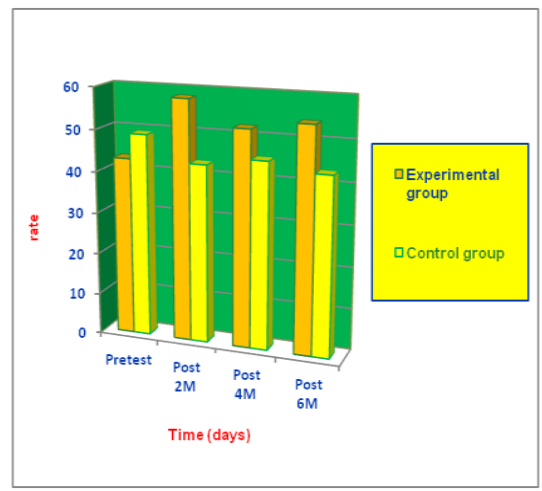

D. The Change of Vegetable Intake

Figure 2. Change of Health Promotion According to the Time Intervals

\section{Discussion}

This aim of this study is to evaluate the clinical application of predictive models for health promotion in patients who had thyroidectomy. This experimental research has been conducted to draw up plans to improve quality of life in thyroid cancer patients.

As a result, stress control was significantly decreased after intervention in subjects compared with before of the intervention. The results showed that clinical information significantly effect in reducing hypertension and in increasing vegetable intake of the experimental group. The significance of health practice on the subjects' body weight control showed after intervention as compared before intervention. The finding was consistent with the result of earlier researches $[11,12]$. These findings suggest that the application of clinical information system may be effective to reduce the obesity and increase the vegetable intake subjects.

The present research showed that the performance ability rate of thyroidectomy can be increased to $52.7-68.4 \%$ by the intervention, which is similar to data reported in the previous studies [1, 3-15]. This study shows that in order to improve the quality of life among women with thyroid cancer, strategies are needed to reduce stress during the long period of treatment and to increase resilience. Therefore, it is necessary to develop practice and specific nursing 
program for women with thyroid cancer to reduce stress and increase resilience. Through these programs, their quality of life will be enhanced.

This study demonstrated the effectiveness of guided imagery in reducing stress among patients who were undergoing thyroidectomy. Therefore, it needs further studies investigating the long-term effects of guided imagery intervention on health practice in patients undergoing thyroidectomy.

The objective measurement on the changes of the behaviors of the patients would be more valuable than mere abstract testimonies that are only responses to the question provided by the programs. Therefore, this paper was proposed important data such as health, information intervention, evaluation, control on stress, and tasks for efficient prevention. These may also be used for the planning report for reduction of thyroid cancer in the future. Based on these results, this paper proposes social skill training program and short-term concentration improvement program for patients with thyroid surgery problems. Thus, this paper revealed that the implemented systematic intervention program of a health information system showed significant positive effects on the life of patients and health behavior.

The research will play an important role in operating new project for thyroidectomy patients and can be extended also for shedding new light on understanding thyroidectomy patients. This model can apply to the theoretical researches which have been used to understand how patients change health behaviors.

\section{Conclusion}

This study was conducted to clarify the clinical effects of predictive models for health promotion in thyroidectomy patients. The results of this study are follows. Firstly, the response rate $(59.2 \%)$ of experimental groups was statistically significantly higher than the response rate $(53.5 \%)$ of control group at female $\left(\mathrm{X}^{2}=6.59, \mathrm{p}=.042\right)$ according to gender of subjects. Secondly, this study identified statistically positive effects of vegetable intake, and blood sugar control by the intervention $(\mathrm{p}<.05)$. Thirdly, the present research showed that the performance ability rate of thyroidectomy can be increased to $52.7-68.4 \%$ by the intervention.

As a result of this information system is appropriate model. The model can be used as an effective method to improve for the reduction of thyroid cancer. This paper, therefore, resulted in significant improvement in the quality of life of thyroidectomy patients and its implications could be used as the basic data for developing patients. So this study will contribute to the model of thyroidectomy patients' health promotion and health intervention strategies and useful information for health educators.

\section{References}

[1] Statistics Korea, Annual Report on the Cause of Death Statistics (2012)

[2] F. Pacini, M. Capezzone, R. Elisei, C. Ceccarelli, D. Taddei and A. Pinchera, "Diagnostic 131Iodine Whole-Body Scan May Be Avoided in Thyroid Cancer Patients Who Have Stimulated Serum Tg Levels After Initial Treatment”, J. Clin Endocrinol Metab, vol. 87, (2002), pp. 14991501.

[3] E Molinaro, MG Castagna, L Agate, R Elisei and C Ceccareli, "Recombinant Human ThyrotropinStimulated Serum Thyroglobulin Combined with Neck Ultrasonography Has the Highest Sensitivity in Monitoring Differentiated Thyroid Carcinoma", J Clin Endocrinol Metab, vol. 88, (2003), pp.3668-3673.

[4] D. Peng, K. Duan and L. Xie, "Improving the Performance of Aggregate Qvaries with Cached Tuples in MapReduce", IJDTA, vol. 16, no. 1 (2013).

[5] V. Nostrand and W. L. Radioiodine in the Treatment of Thyroid Cancer, Endocrinol Metab Clin North Am, vol.36, (2007), pp. 807-822. 
[6] M. Urhan, S. Dadparvar, A. Mavi, M. Houseni, W. Chamroonrat and A. Alavi, "Iodine-123 As A Diagnostic Agent in Differentiated Thyroid Carcinoma : A Comparison with Iodine-131 PostTreatment Scanning and Serum Thyroglobulin Measurement”, Eur J Nucl Med Mol Imaging, vol. 34, (2007), pp. 1012-1017

[7] N. Ali, C. Sebastian, R.R. Foley, I. Murray, A.L. Canizales and P.J. Jenkins, "The Management of Differentiated Thyroid Cancer Using 1-123 for Imaging to Assess the Need for 1-131 Therapy", Nucl Med Commun, vol. 27, (2006), pp. 165-169.

[8] C.-F. Wu, C.-T. Lin and P.-M. Wang, Applying Multi-Criteria Method to the Decision of Assessment Tools for High-Care Student Groups, Vol. 6, No. 3, 1, 14, IJHIT (2013).

[9] Manole D, Schildknecht B, Gosenell B, Adams E and Derwahl M, Estrogen Promotes Growth of Human Thyroid Tumor Cells by Different Molecular Mechanisms, Journal of Clinical Endocrinology and Metabolism, Vol. 86, 1072, 1077 (2001).

[10]B. Pieper, M. Sieggreen, B. Freeand, P. Kulwicki, M. Frattaroli and D. Sidor, "Discharge Information Needs of Patients After Surgery, Journal of Wound Ostomy \& Continence Nursing", vol. 33, (2006), pp. 81- 289.

[11]P. N. Schultz, "Providing Information to Patients with A Rare Cancer : Using Internet Discussion Forums to Address the Needs of Patients with Medullary Thyroid Carcinoma", Clinical Journal of Oncology, vol. 6, no. 4, (2002), pp. 220-222.

[12]L. Mahnane, M. Tayedb, L Trigano and P. Trigano, "A Model of Adaptive e-Learning Hypermedia System based on Thinking and Learning Styles", IJMUE, vol. 8, no. 3, (2013), pp. 339,350 .

[13] S.M. Rawl, B.A. Given, C.W. Given, V.L. Champion and S.L. Kozachik, "Intervention to Improve Psychological Functioning for Newly Diagnosed Patients with Cancer", Oncology Nursing Forum, vol. 29, (2002), pp. 967, 975.

[14]L. Seong Ran, "Clinical Application of Predictive Models for Health Promotion of Patients Undergoing Thyroidectomy", Healthcare and Nursing International Workshop (2013) December 11-13, Jeju Island, Korea.

[15]P. N. Shultz , C. Stava and R. Vassilopoulou-Sellin, "Health Profiles and Quality of Life of 518 Survivors of Thyroid Cancer", Head \& Neck, vol. 25, (2003), pp. 349-356.

\section{Author}

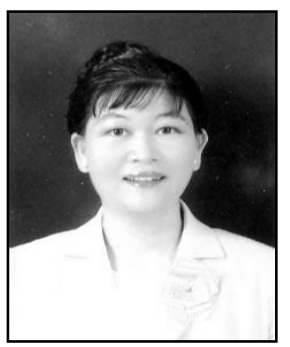

Seong-Ran Lee, she received the B.S. degree in Consumer Science from Seoul National University, Korea in 1987. She received the M.S. degree in Public Health from Seoul National University, Korea in 1992 and Ph.D in the same area from Catholic Medical College, Seoul, Korea in 2000. Currently, she is Associate Professor in the Department of Medical Information, Korea. Her present research interest is medical information. 
International Journal of Bio-Science and Bio-Technology Vol.6, No.3 (2014) 